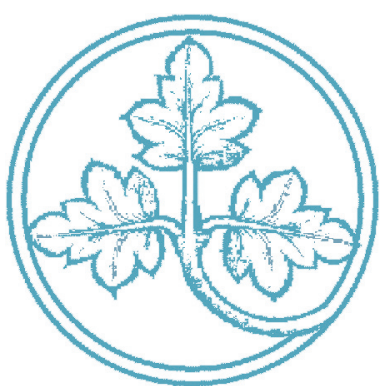

How to Determine whether

Regional Markets are Integrated? Theory and Evidence from European Electricity Markets

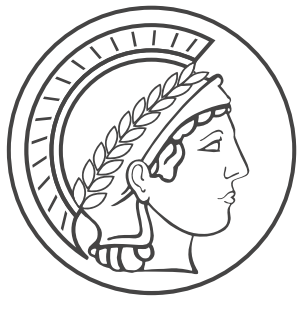




\section{How to Determine whether Regional Markets are Integrated? Theory and Evidence from European Electricity Markets}

Georg Gebhardt / Felix Höffler

September 2007 


\title{
How to Determine whether Regional Markets are Integrated? Theory and Evidence from European Electricity Markets
}

\author{
Georg Gebhardt $\mathrm{t}^{1}$ and Felix Höffler ${ }^{2}$ \\ September, 2007
}

\begin{abstract}
Prices may differ between regional markets if transport capacities are limited. We develop a new approach to determine to which extent such differences stem from limited participation in cross-border trader, i.e. lack of integration, rather than from bottlenecks. This approach considers both sets of prices (transport and spot prices). We derive a theoretical integration benchmark for the typical case where transportation markets clear before the product markets, using Grossman's (1976) notion of a rational expectations equilibrium. We compare the benchmark to data from European electricity markets, where spot prices differ between countries and interconnection capacities between national markets are scarce. The data reject the integration hypothesis: Capacity prices contain too little information about the price differential; this indicates that well informed traders, e.g. large national incumbents, do not engage in cross-border trade. While unprofitable in the short run, this behavior may result from anti-competitive long run strategies.

Keywords: Market integration, electricity markets, interconnector, competition policy, rational expectations equilibrium

JEL-Classification: G14, D84, L94

\footnotetext{
${ }^{1}$ Department of Econmics, University of Munich, Ludwigstr. 28 (Rgb), D-80539 Munich, Tel.:++49 (0)892180 2876, georg.gebhardt@lrz.uni-muenchen.de

${ }^{2}$ Chair of Regulatory Economics, WHU - Otto Beisheim School of Management - Burgplatz 2, 56179 Vallendar, Germany. ++49(0)261 6509220. felix.hoeffler@whu.edu . Financial support from Deutsche Forschungsgemeinschaft through SFT-TR 15 is gratefully acknowledged. We would like to thank Martin Hellwig and Klaus M. Schmidt for helpful discussions and Jan Schikora for excellent research assistance.
} 


\section{Introduction}

The integration of regional markets into a single supraregional market features high on the agenda of policy makers; integrated markets allow more efficient production and increase competition. A case in point is the European market for electricity. In its "Sector Inquiry", published in January 2007, the EU commission states:

Well functioning energy markets that ensure secure energy supplies at competitive prices are key for achieving growth and consumer welfare in the EU. To achieve this objective the EU decided to open up Europe's gas and electricity markets to competition and to create a single European energy market. (EU, Sector Inquiry 2007, para.1)

However, "...the objectives of the market opening have not yet been achieved." (ibid., para.2). Spot market prices still differ significantly among the member countries. At least some of this price divergence is caused by limited interconnector capacities between the national electricity grids; exactly how much, remains an open question. Limited interconnector capacity could just mask a lack of participation in cross-border trade. Similar questions arise in other markets that require a dedicated transportation infrastructure with bottlenecks, e.g., the markets for oil or natural gas. These examples have in common that markets for transportation capacity have to clear before the final product markets opens. The same holds for electricity markets in Europe, where auctions for scarce interconnector capacity take place before the spot markets.

In this paper, we investigate the question of market integration by first proposing a theoretical benchmark and then empirically applying it to the case of the European electricity market; however, our new approach could be used in any market with a similar timing. For the test, we consider both interconnector and spot market prices. The theoretical integration benchmark is based on a standard idea in economics: Prices aggregate information. All traders value interconnector capacity at the spot market price differential between the two sides of the border. Every trader has some private information about this price differential, but 
there is no aggregate uncertainty since all traders together determine spot market prices. If interconnector prices aggregate the traders' information, interconnector prices should perfectly predict the price differential in the direction in which trading is profitable, and should be zero in the opposite direction 3

If not all traders undertake cross-border trades - this is our definition of imperfect integration - interconnector prices contain less information; however, there could be a confounding source of noise: Since traders must buy interconnector capacity before they can trade in the spot markets, they may receive additional information between the two trades; in this case, even if all traders try to buy interconnector capacity, interconnector prices cannot contain this additional information. Yet, the arrival of additional information has a second effect - traders assign an option value to interconnector capacity: Suppose, in the interconnector market, a trader expects that the spot price will be higher in country A, but is aware that additional information, arriving before the spot market, may invert her estimate of the price differential; this trader is willing to pay a positive price also for capacity into country B. Thus, if we observe that interconnector prices are only a noisy predictor of the price differential but that there is no corresponding option value, i.e., the lower interconnector price is zero, we can conclude that our integration benchmark is violated.

We compare this theoretical benchmark for integration to data from the DanishGerman and the Dutch-German borders for the years 2002-2006. We have price data resulting from interconnector capacity auctions and the respective spot markets, in each case for hourly, day-ahead electricity contracts. In the first two countries, electricity prices are very similar on average; on the second border, spot market prices in the Netherlands are on average significantly higher than in Germany.

The stylized facts of the data are not in line with the integration benchmark. The lower of the two interconnector prices is almost always zero or very close to zero, suggesting that cross-border traders expect little new information to arrive. At the same time, interconnector prices predict the spot market price differentials

\footnotetext{
${ }^{3}$ We model this using Grossman's (1976) notion of a rational expectations equilibrium.
} 
on average correctly but only with a lot of noise, suggesting that cross-border traders possess a limited amount of information. We conclude that the missing information is private information of market participants who do not conduct cross-border trades.

In order to make this reasoning more precise, we calibrate our theoretical model to find out exactly how much information arrives between the interconnector and the spot markets, and how much information the interconnector prices actually contain. We find that the information cross-border traders receive after they have bought capacity but before they trade across borders is essentially zero. The information cross-border traders possess when they buy capacity is only between $24 \%$ (Germany/Netherlands) and 36\% (Germany/Denmark) of the total variance of the price differential. Thus, our main conclusion is that traders with a large amount of relevant information do not participate in the interconnector auction although they could generate profits based on their information. To explain the absence of these informed traders is beyond the scope of our paper; however, we argue that cross-border collusion would provide a plausible motive for such behavior; moreover, the suspicion of cross-border collusion is shared by many competition authorities. $4^{4}$

Our results are complementary to the theoretical analysis of the competitive effects of limited transmission capacity developed by Borenstein, Bushnell, and Stoft (2000), who show that expanding transmission capacity between two otherwise separated markets may result in a large reduction of market power. The authors caution, however, that they have "considered only one-shot Nash equilibria $(. .$.$) . In reality, the firms that compete in electricity markets will do so$ repeatedly and, thus, may be able to reduce rivalry through the threat of retaliation. To the extent that firms can reach more cooperative outcomes through such supergame strategies, the competitive effects of transmission lines (...) are likely to be dampened." (p. 320). Our analysis provides evidence that multi-period considerations are likely to play a role in electricity markets.

\footnotetext{
${ }^{4}$ We provide references in the Discussion.
} 
Due to the high policy relevance of electricity interconnectors, they have drawn a lot of attention in the applied literature. An introduction to "interconnector economics" can be found in Turvey (2006), or, more generally, in Crampes and Laffont (2001). Hobbs, Rijkers, and Boots (2005) and Höffler and Wittmann (2007) discuss the effects of different institutional designs for the interconnector auctions on the market outcome. None of these approaches directly tackles the question of how to explain the relation between spot market prices and interconnector prices, which is the main contribution of our paper.

The remainder of the paper is organized as follows: In section 2 we introduce the institutional set up of the cross-border electricity trade in Europe. Section 3 describes the data and the main stylized facts. Section 4 contains the theoretical model and its predictions. Section 5 presents the calibration of the model and the main empirical results. The findings are discussed in section 6 ; section 7 concludes.

\section{European Electricity Markets}

The European Union has clearly spelled out that a unified electricity market should be implemented in Europe. Since electricity can be transported at the high voltage level at very low cost, there could be supraregional or supranational electricity markets. A geographically large market, based on imports and exports of electricity, could increase the level of competition and increase efficiency by supplying electricity by the least-cost producer.

Electricity should, as far as possible, flow between Member States as easily as it currently flows within Member States. Improved cross border flows will increase the scope for real competition which will drive economic efficiency in the sector... (European Commission 2004, 3)

However, it is obvious that this goal has not been achieved yet. In Europe, wholesale electricity markets are still largely national markets. There exist different electricity exchanges in almost all countries, and the spot market prices 


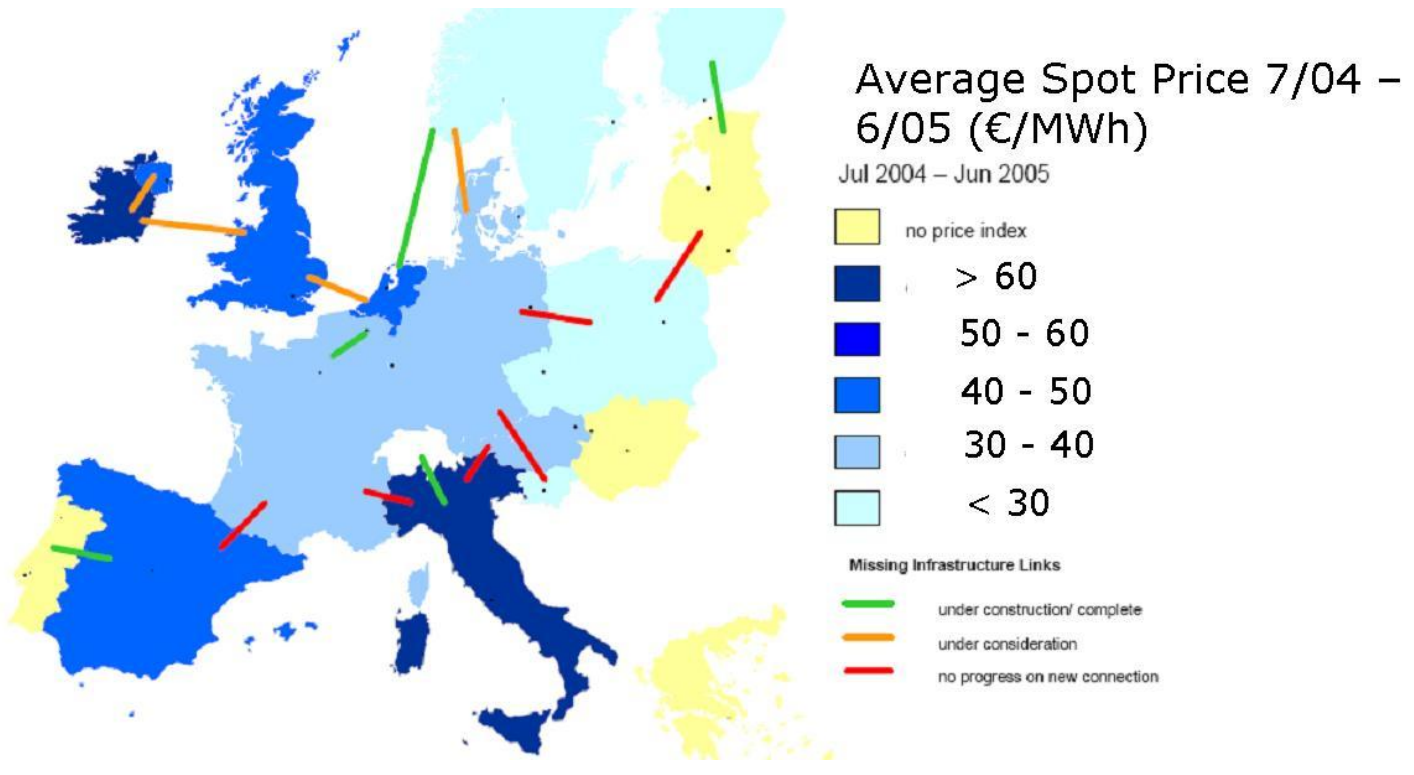

Figure 1: Differences in European Electricity Spot Market Prices

differ considerably, up to more than 100 percent. Figure 1 shows the results of an investigation of this issue by the European Commission $5^{5}$

An important reason for the fragmentation of the European electricity market are limited interconnector capacities. In its "Sector Inquiry", the EU Commission finds that "In electricity, integration is hampered by insufficient interconnector capacity" (Commission" 2007, para. 23). While there are - usually - no bottlenecks within national electricity grids, there exist only limited capacities for the exchange of electricity between national grids. There are historical reasons for this: "Transmission networks were not developed in order to support efficient trade", but rather to optimize intra-country operations (CEER 2003, par. 8). With the liberalization of national electricity markets, increasing interest in the

\footnotetext{
${ }^{5}$ Communication from the EU Commission to the Council and the EU Parliament. Report on progress in creating the internal gas and electricity market, COM (2005) 568 final (15/11/2005), p.5. Similar findings are in the "Sector Inquiry" of 2007, Part 2, p. 180 (Commission" 2007). In a recent, more rigorous study, Zachmann (2007) shows that, by and large, there was no convergence of wholesale prices in Europe for the period we investigate (2002-2006).
} 
international trade of electricity has turned cross-border transmission capacities into a bottleneck. At most interconnectors, the scarce capacities are now allocated in auctions 6

Although limited interconnector capacities set an upper bound for trading volumes between countries, an important question is whether differences in prices between national electricity markets, and therefore limited cross-country competition, is only due to congestion. The availability of interconnector pricing data and of spot market prices allows us to investigate this question. We focus on two interconnectors and the interaction between the spot markets: (i) Denmark (West) and Germany, with the spot markets 'Nord Pool West' and 'EEX', and (ii) the Netherlands and Germany, with the spot markets 'APX' and 'EEX'. Figure 1 illustrates that these two examples captures the main interesting cases, i.e. the comparison of markets with - on average - similar spot prices (Denmark and Germany) and markets with - on average - different price levels (Netherlands and Germany) ${ }^{7}$

At the Danish-German interconnector and at the Dutch-German interconnector there are day-ahead auctions for hourly contracts, i.e. for the right to transport 1 Mega Watt for a specific hour the next day. Holding such a transmission right is compulsory if one wants to engage in cross-border sales on the electricity exchange; if, for instance, a Danish power producer wants to offer electricity on the German EEX, it has to hold sufficient transmission rights to be able to fulfill a successful bid.

Therefore, the interconnector auction takes place first; afterwards firms get informed about the auction outcome, and on that basis might submit bids in the

\footnotetext{
${ }^{6}$ The scarcity of capacity is also due to inefficiencies in the allocation mechanism. There is clear evidence that even heavily 'congested' interconnectors are rarely used up to physical capacity. For this and alternative allocation mechanisms, see Höffler and Wittmann (2007).

${ }^{7}$ These are physical hourly contracts in which a bidder has to specify day ahead a demand / supply function for electricity of a particular hour. Thus, there are essentially 24 markets per day. Bids have to be continuous. Delivery of successful bids is on the high voltage level to a virtual trading point. This implies that for trades on the electricity exchange, no transportation cost within a country has to be incurred (any transportation cost towards the customer on lower voltage levels has to be borne by downstream companies). Therefore, the spot market prices are comparable.
} 


\begin{tabular}{|c|c|c|c|}
\hline $\begin{array}{c}\text { Time } 1 \\
\text { Intercon. } \\
\text { Auction }\end{array}$ & $\begin{array}{r}\mathrm{Ti} \\
\mathrm{S} \\
\mathrm{M}\end{array}$ & $\begin{array}{l}\text { ne } 2 \\
\text { pot } \\
\text { irket }\end{array}$ & \\
\hline $\begin{array}{lc} & 1 \\
9: 30 & 10: 00 \\
\text { bids must beallocation of } \\
\text { submitted to } & \text { capacity } \\
\text { interconnector } & \\
\text { auction }\end{array}$ & $\begin{array}{c}12: 00 \\
\text { bids must be } \\
\text { submitted to } \\
\text { spot market } \\
\text { auctions }\end{array}$ & $\begin{array}{l}12: 15 \\
\text { results of } \\
\text { spot market } \\
\text { auction } \\
\text { announced }\end{array}$ & $\begin{array}{l}\text { Next Day } \\
\text { physical } \\
\text { delivery }\end{array}$ \\
\hline
\end{tabular}

Figure 2: Timing of spot markets and interconnector auction

adjacent market's spot market. Figure 2 shows the timing of the actions. Note that there is only a time frame of 2.5 hours between the submission of the bids for the two auctions. Thus, differences in information between the two auctions must be due to interim information arriving precisely between 9:30 a.m. and 12.00 a.m.

There is certainly no aggregate uncertainty regarding the spot market prices, since all traders jointly determine the spot market prices. Any random events (e.g. like actual weather conditions, unexpected power plant outages, etc.) have to be handled after the spot market has closed, on the day of delivery. This is done by the electricity system operator when dispatching, i.e. calling power plants to produce electricity, in real time.

\section{The Data}

Our data for the spot prices stem from the respective electricity exchanges, APX (Netherlands), EEX (Germany), and NordPool (Denmark). They are in current Euro / MW for each respective hour in the day ahead trading for the time from the first hour (0-1) on $1 / 1 / 2002$, to the last hour (23-24) on 30/9/2006, implying 41,616 observations. Interconnector prices were provided by the operators of the interconnector auctions 8 and also contain 41,616 observations, one for every hour

\footnotetext{
${ }^{8}$ We use the data for the interconnector between the German E.ON network and the Dutch network. There is also an interconnector connecting the German RWE network and the Dutch
} 
of the same time period. The time 2002-2006 covers almost the whole history of interconnector auctions at these borders. Table 1 contains the summary statistics for the prices.

Table 1: Summary Statistics

\begin{tabular}{|c|c|c|c|c|c|}
\hline & Region & Mean & Std. Dev. & Min. & Max. \\
\hline \multirow[t]{3}{*}{ Spot Price } & Denmark & 33.6 & 17.1 & 0 & 597 \\
\hline & Germany & 35.0 & 29.3 & 0 & 2000 \\
\hline & Netherlands & 43.2 & 59.4 & 0 & 2000 \\
\hline Interconnector & Den $\rightarrow$ Ger & 4.3 & 13.3 & 0 & 500 \\
\hline \multirow[t]{3}{*}{ Prices } & Ger $\rightarrow$ Den & 2.1 & 5.2 & 0 & 64 \\
\hline & $\mathrm{NL} \rightarrow \mathrm{Ger}$ & 0.04 & 0.09 & 0 & 5 \\
\hline & Ger $\rightarrow$ NL & 6.7 & 25.7 & 0 & 639 \\
\hline
\end{tabular}

As noted before, the price is on average almost the same in Germany and Denmark, while on average the price is $23 \%$ higher in the Netherlands than in Germany. Average interconnector prices can be ordered according to the average spot market price difference: they are on average highest for trade from Germany to the Netherlands, followed by trade from Denmark to Germany. They are on average close to zero for trade from the Netherlands to Germany.

Trade between the different regions should depend on the difference of the different spot market price levels. Table 2 therefore provides the summary statistics for the difference of the spot market prices (Spotdiff) and of the interconnector prices (Interdiff) for both borders. For the theoretical analysis, it will turn out to be important to distinguish between the higher and the lower interconnector price at each point in time. The summary statistics for these data are also provided in Table 2. Intermax (Intermin) describes - for each hour - the price for capacity in the direction with the higher (lower) price. To allow comparisons with Interdiff, the interconnector price from Germany to another country is reported network. 
as a negative value, the interconnector price in the opposite direction as a positive value; e.g. suppose the price from Germany to Denmark was $1.5 €$ while in the opposite direction it was $1.0 €$, then Intermax is $-1.5 €$ and Intermin is $1 €$.

Table 2: Price Differences

\begin{tabular}{lrrrr}
\hline \hline & \multicolumn{2}{c}{ Ger-Den } & \multicolumn{2}{c}{ Ger-NL } \\
& Mean & Variance & Mean & Variance \\
\hline Spotdiff & 1.4 & 606.5 & -8.28 & $2,777.9$ \\
Interdiff & 2.14 & 191.3 & -6.61 & 658.0 \\
Intermin & -0.01 & 0.13 & 0.02 & 0.05 \\
Intermax & 2.18 & 219.5 & -6.63 & 658.2 \\
\hline \hline
\end{tabular}

It is remarkable that the variance of the smaller of the two prices is by far lower than the variance of the larger of the two prices. This reflects that the lower of the two prices at each interconnector is essentially zero, or very close to zero almost always. Table 3 shows the frequency of zero prices (or prices close to zero) for the lower of the two interconnector prices. Almost half of the time, the price for interconnector capacity is exactly zero in one direction. While in the GermanDanish case this can be either direction, in the German-Dutch case it is (almost always) the price from the Netherlands to Germany which is zero, while the price in the opposite direction is strictly positive. Because the lower of the prices is mostly close to zero, the variance of the difference of the two prices is (Interdiff) essentially equal to the variance of the larger of the two prices (Intermax) ${ }^{9}$

\footnotetext{
${ }^{9} \mathrm{~A}$ second feature of the data is that the variance of the larger of the two prices is considerably smaller than the variance of the spot price differential. Since we can interpret interconnector capacity as a risky asset that has the realized price differential as a payoff, this implies that interconnector capacity is an asset whose price has a lower volatility than its payoff. This is highly unusual because financial assets almost always display excess volatility; e.g. stock price volatility is larger than dividend volatility. Similar results have been obtained for assets ranging from bonds to foreign exchange rates (see Shiller 1981 for an overview); moreover, Cochrane (1991) argues that excess volatility is just the flip-side of the most common deviations from the efficient market hypothesis, such as bubbles and return predictability. This finding makes it very unlikely that any of these well known anomalies can account for the data observed on the interconnector capacity markets; rather these data require an explanation that is specific to cross-border trades in electricity.
} 
Table 3: Frequency of zero interconnector prices

\begin{tabular}{lcccc}
\hline \hline & \multicolumn{2}{c}{ Den - Ger } & \multicolumn{2}{c}{ NL - Ger } \\
Interconnector Price & $\#$ & $\%$ & $\#$ & $\%$ \\
\hline Min $=0.00 € /$ MWh & 17,706 & $42.5 \%$ & 19,242 & $46.2 \%$ \\
Min $<0.03 € /$ MWh & 32,505 & $78.1 \%$ & 30,967 & $74.4 \%$ \\
Min $<0.05 € /$ MWh & 34,877 & $83.8 \%$ & 33,068 & $79.5 \%$ \\
\hline Total & 41,616 & $100 \%$ & 41,616 & $100 \%$ \\
\hline \hline
\end{tabular}

Finally, we can investigate with a regression analysis how well the interconnector prices predict potential profits from cross-border trades. Figures 3 and 4 show the data for both interconnectors. The horizontal axis shows the higher of the two interconnector prices. The vertical axis shows the realized profit from using the capacity. All points above the horizontal axis reflect 'correct' price constellations: the price for usage of the interconnector was non-zero in the direction of the market where the spot price turned out to be higher. Note that only points above a line from the origin with slope one reflect ex-post profitable usage of the interconnector (the interconnector price was below the gain from exploiting the spot market price difference). For points below the horizontal axis, the price for usage of the interconnector was positive for the direction in which the spot market turned out to be smaller, reflecting 'mistakes'.

The interconnector prices predict on average the price differential in the spot market correctly (the coefficient is close to unity). For the Dutch case, the intercept is positive, which would be in line with the assumption of some fixed trading costs (only if the spot market price difference exceeds some threshold will traders start to trade). The slightly negative intercept in the case of Denmark is more difficult to explain in such a simple model.

We can summarize the data discussion with three stylized facts: 


\section{Germany-Denmark}

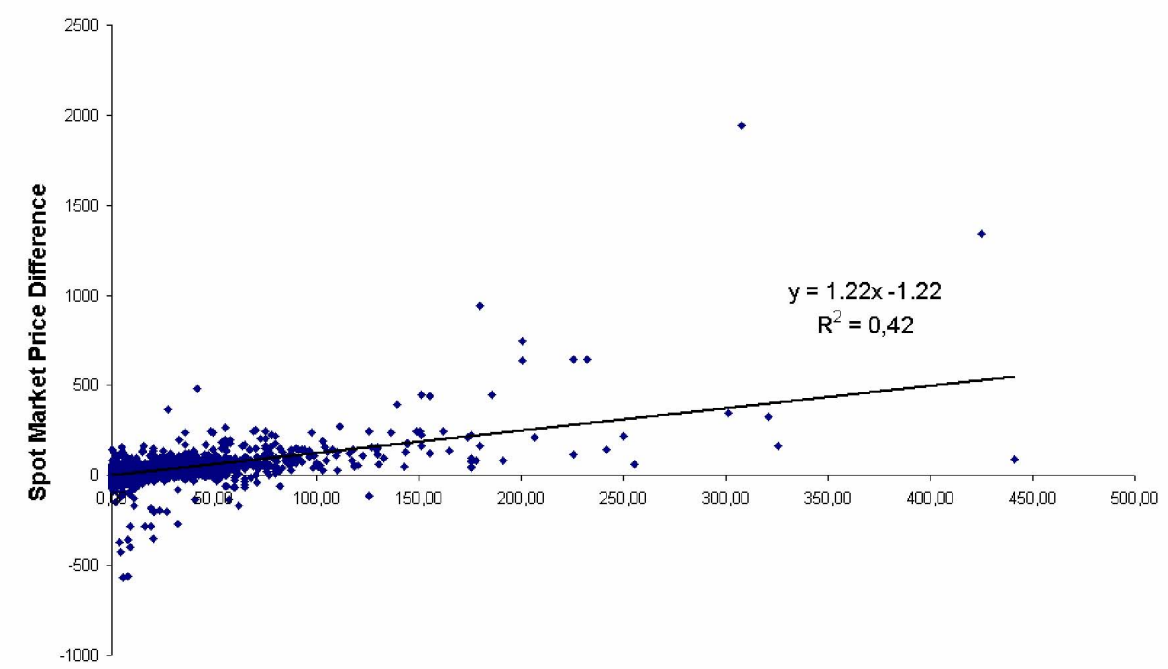

Max. Interconnector Price

Figure 3: Denmark-Germany: Interconnector Prices and Spot Market Prices 20022006

Germany-NL

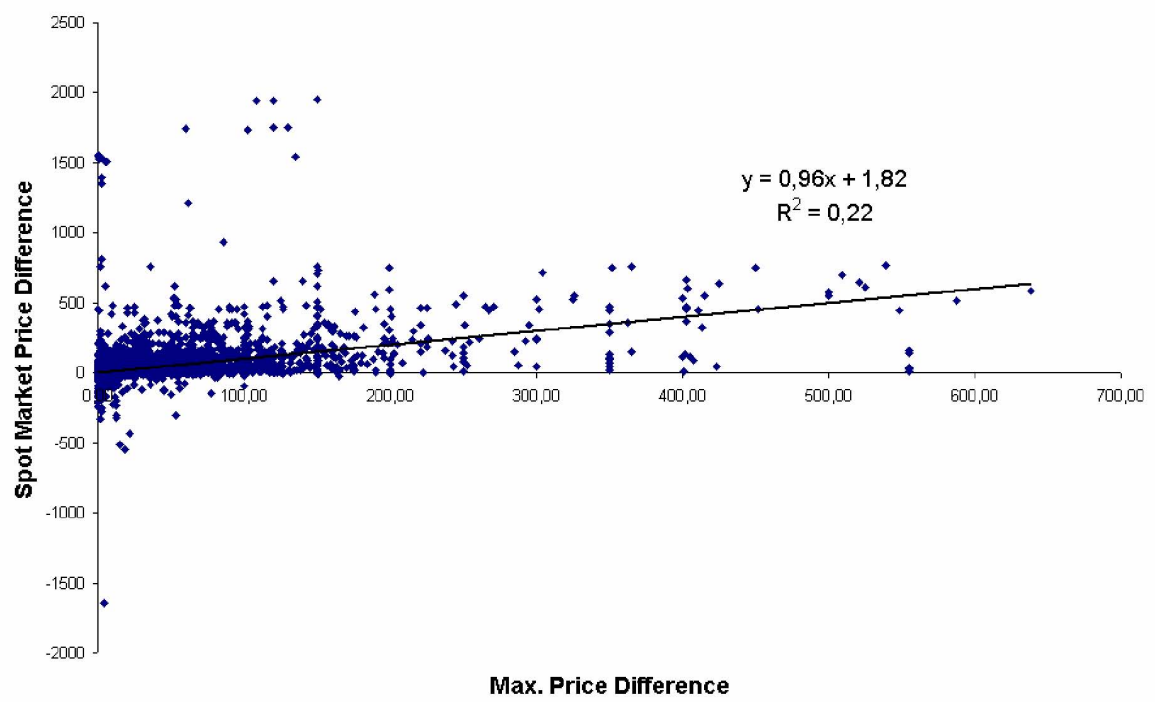

Figure 4: Netherlands-Germany: Interconnector Prices and Spot Market Prices 2002-2006 
1. The difference in the interconnector prices predicts the price differential very well in the sense that a regression of the price differential on the interconnector price yields a highly significant coefficient of about one.

2. The correlation is, however, quite weak, i.e. there is a lot of noise.

3. The lower interconnector price is close to zero almost always.

\section{Model}

We model the cross-border trade of electricity between two countries, home and abroad $(C \in\{H, A\})$, as two sets of markets that open sequentially. In the second stage, every market participant, indexed by $n \in\{1, \ldots, N\}$, trades in at least one spot market. However, only those market participants that have acquired interconnector capacity in the first stage can engage in cross-border trade. In the spot markets, demand and cost functions depend on a random shock $\tilde{s}$. We are interested in the outcomes, prices $p^{H *}$ and $p^{A *}$, of the second stage spot markets only in so far as they influence the interconnector fees in the first stage; i.e., we care only about the price differential between the two spot markets that obtains if the shock $s$ is realized:

$$
\Delta p(s) \equiv p^{H *}(s)-p^{A *}(s) .
$$

Let $s$ consist of $N+1$ components:

$$
s=\left(s_{1}, \ldots, s_{N}, s_{I}\right) .
$$

Before time one, $s_{n}$ is revealed to firm $n$, but not to the other firms. This could be the level of firm $n$ 's demand or factors influencing firm $n$ 's supply, like power plant outages. All firms learn interim information $s_{I}$ between time one and two; i.e., after they have bought interconnector capacity, but before they have to decide wether to use it by submitting cross-border trades. The variable $s_{I}$ could be 
interpreted as information such as more up-to-date weather forecasts 10

The functional form and distribution of $s$ and $\Delta p(s)$ are characterized by three assumptions: (1) The price differential is the sum of a deterministic component $\delta$ and the shocks $s_{1}, \ldots, s_{N}$ and $s_{I}$ :

$$
\Delta p(s) \equiv \delta+\sum_{n} s_{n}+s_{I}
$$

(2) the firm-specific information $s_{1}, \ldots, s_{N}$ takes the form of random variables i.i.d. from a Normal distribution with mean zero and variance $\frac{\sigma^{2}}{N} ;(3)$ public interim information $s_{I}$ is independently drawn from a Normal distribution with mean zero and variance $\sigma_{I}^{2}$. Note that the spot market price differential is assumed to be independent of cross-border trades 11

During the first stage, all market participants can buy interconnector capacity in both directions on two competitive markets, capacities that may allow them to profit from spot price differentials by engaging in cross-border trades. The maximum interconnector capacity is $\bar{K}$ in either direction. Let $k_{n}$ be the actual use of the interconnector by firm $n$; a positive $k_{n}$ indicates that electricity flows from abroad to home. Let $K=\sum_{n} k_{n}$ be the total net use of the interconnector. Each trader $n$ can hold no-interest-paying cash or buy capacity in either or both directions. We denote the (non-negative) capacity that trader $n$ buys to send electricity from home to abroad by $k_{n}^{H A}$ and the (non-negative) per unit fee she pays by $f^{H A}$. Capacities and fees in the reverse direction are called $k_{n}^{A H}$ and $f^{A H}$, respectively. Before time one, each trader $n$ observes the component $s_{n}$ of the shock, an information that she can use to decide on her capacity demands at time one. Between times one and two, interim information $s_{I}$ is revealed to all traders and, at time two, they have to decide on $k_{n} \in\left[-k_{n}^{H A}, k_{n}^{A H}\right]$, the net capacity they

\footnotetext{
${ }^{10}$ We use public interim information for simplicity only. We get qualitatively the same results with private interim information.

${ }^{11}$ This assumption can be justified by the fact that interconnector capacity is small relative to the total spot market. If we relax this assumption, the traders do not necessarily exhaust the capacity of the interconnector for a range of values of $s$, because they expect a price differential of zero. This introduces a discontinuity that complicates the exposition considerably, while all the results continue to hold qualitatively.
} 
want to use for cross-border trades. Trader $n$ 's capacity purchase and utilization decisions result in time three profits of

$$
\Pi=\Delta p \cdot k_{n}-f_{n}^{H A} \cdot k_{n}^{H A}-f_{n}^{A H} \cdot k_{n}^{A H} .
$$

Assuming that all market participants are risk neutral, each buys interconnector capacity to maximize $E(\Pi)$.

To characterize the equilibrium prices on the market for interconnector capacity, we use the concept of the fully revealing rational-expectations equilibrium, introduced by Grossman (1976). It requires that traders act as price takers and stipulates market clearing; i.e., given equilibrium fees $f^{H A *}$ and $f^{A H *}$,

$$
\sum_{n} k_{n}^{H A}=\sum_{n} k_{n}^{A H}=\bar{K}
$$

In addition to market clearing, the definition of a rational-expectations equilibrium demands that the traders use all available information, in particular, the information contained in the realized market prices; furthermore a fully revealing rational-expectations equilibrium requires that the price is a sufficient statistic for the information of each trader. In such an equilibrium, no trader has a desire to revise her demand once the realized fees become known, and even if the trader could observe the signals of all other traders, she would still not want to revise her demand 12

\footnotetext{
${ }^{12}$ The fully revealing rational-expectations equilibrium makes a prediction of the resulting market price but it remains silent on how these prices come about; in particular, demand curves are not well specified. This problem has already been extensively studied in the literature, and Hellwig (1980) has shown that the fully revealing rational expectations equilibrium can be interpreted as the limit of a slightly perturbed market as the perturbation goes to zero. In the perturbed market, traders have well defined demand functions which are used by the Walrasian auctioneer to derive equilibrium prices and quantities. We consider the direct use of the unperturbed model as a useful shortcut whose simplicity compensates for its reduced intuitive appeal.
} 


\subsection{No Interim Information}

For the predictions of the theoretical integration benchmark - the fully revealing rational-expectations equilibrium - regarding the relation between spot market price differentials and the interconnector prices, we start with the simplest case. We assume that the information consists only of private information $s_{1}, \ldots, s_{N}$. Let $S_{N}=\sum_{n} s_{n}$ denote the sum of all private signals. If no interim information arrives at the market between times one and two, the following proposition characterizes stage one prices:

Proposition 1 If $\sigma_{I}^{2}=0$, the interconnector fees equals $\Delta p$ in one direction and zero in the other; i.e.

$$
\begin{aligned}
f^{A H^{*}} & =\max \left\{\delta+S_{N}, 0\right\} \text { and } \\
f^{H A^{*}} & =\max \left\{-\delta-S_{N}, 0\right\},
\end{aligned}
$$

and the variance of $\widetilde{\Delta p}$ conditional on the equilibrium fees $f^{H A^{*}}$ and $f^{A H^{*}}$ equals zero,

$$
\operatorname{Var}\left(\widetilde{\Delta p} \mid f^{H A^{*}}, f^{A H^{*}}\right)=0 \text {. }
$$

Proof. See Appendix.

Without interim information, no new information arrives after the market for interconnector capacity closes. Since the interconnector prices aggregate all relevant information, traders know the price differential when they have to decide whether to submit cross-border trades, and they will trade only in the one direction that is profitable. The price in this direction must be equal to the profit; i.e., the price differential. Capacity in the other direction is not used and its price must be zero in equilibrium.

\subsection{Interim Information}

If interim information arrives at the market between times one and two, the interconnector prices can no longer contain all the information. Interconnector prices are characterized by the following proposition. 
Proposition 2 If $\sigma_{I}^{2}>0$, the interconnector fees equal

$$
\begin{aligned}
& f^{A H^{*}}=\int_{\delta+S_{N}}^{\infty}\left[\delta+S_{N}+s_{I}\right] \phi\left(\frac{s_{I}}{\sigma_{I}}\right) d s_{I} \text { and } \\
& f^{H A^{*}}=-\int_{-\infty}^{-\delta-S_{N}}\left[\delta+S_{N}+s_{I}\right] \phi\left(\frac{s_{I}}{\sigma_{I}}\right) d s_{I},
\end{aligned}
$$

where $\phi(\cdot)$ is the p.d.f. of the standard Normal distribution.

Proof. See Appendix.

As long as there is interim information, fees in both directions are strictly positive because owning capacity entails an option value. When traders decide whether to use the capacity they have bought, they have observed $s_{I}$. Therefore, they know the realization of $\Delta p$ and they use the capacity in the profitable direction only. Because traders can leave capacity idle, they can never lose by owning capacity but they may profit from it. As the support of $s_{I}$ is (theoretically) unbounded ${ }^{13}$ for any realization of $S_{N}$ there is a strictly positive probability that capacity in either direction will become profitable, and traders are willing to pay a strictly positive price for capacity in both directions at time one. The larger the variance of $s_{I}$, the less important is ex ante information $\left(s_{1}, \ldots, s_{N}\right)$, and the closer both fees are to each other in equilibrium.

\subsection{Limited Participation - No Interim Information}

In the light of the model presented so far, the empirical observations from Section 3 that the lower of the two interconnector fees is almost always zero or close to zero suggests that little interim information arrives between 9:30, when traders submit interconnector bids, and 12:00, when they submit spot market bids. However, if all the information is available to traders at 9:30, it should be aggregated into interconnector fees, and the fees should predict the price differential without noise.

\footnotetext{
${ }^{13}$ As Figures 3 and 4 indicate, there are rare occasions where possible gains from cross-border trader become very large; the highest gain for trading from Denmark to Germany was $€ 568$, for the opposite direction $€ 1,946$; for Netherlands to Germany, the maximum gain was $€ 1,954$, and in the opposite direction $€ 2,778$ (all values per MWh).
} 
As noted in Section 3, this is not the case; the interconnector fees' prediction of the price differential is very noisy. To replicate the qualitative features of the observed interconnector fees, we modify our framework to include the possibility that not all firms will be participating in the interconnector auction.

If some second stage market participants abstain from the interconnector auction, their information cannot be contained in the interconnector prices. There are two sets of second stage market participants: Those $\hat{N}$ who take part in the first stage and those $N-\hat{N}$ who do not. Let us denote the sum of all private signals of the $\hat{N}$ firms participating in the market by

$$
S_{\hat{N}}=\sum_{n=1}^{\hat{N}} s_{n}
$$

We can then characterize the equilibrium fee structure in the following proposition: Proposition 3 If $\sigma_{I}^{2}=0$ and only $\widehat{N}<N$ traders participate in the interconnector auction, the interconnector fee equals

$$
\begin{aligned}
f^{A H^{*}} & =\max \left\{\delta+S_{\hat{N}}, 0\right\}, \text { and } \\
f^{H A^{*}} & =\max \left\{-\delta-S_{\hat{N}}, 0\right\}
\end{aligned}
$$

and the variance of $\widetilde{\Delta p}$ conditional on the equilibrium fees $f^{A H^{*}}$ and $f^{H A^{*}}$ equals the variance of the information of the missing traders, i.e.

$$
\operatorname{Var}\left(\widetilde{\Delta p} \mid f^{H A^{*}}, f^{A H^{*}}\right)=\frac{N-\widehat{N}}{N} \sigma^{2} .
$$

Proof. Identical to the proof of Proposition 2, except that $\widehat{N}$ takes the place of $N$.

Although we assumed no interim information, the interconnector prices can no longer perfectly predict the spot market price differential, since the information of the non-participating traders is missing. However, the prediction should be correct on average, just with some noise. The amount of the noise depends on the number on non-participating traders. Even though there is noise, the price 
for one direction is always zero. The missing information (which is responsible for the noise) is revealed only in the spot markets. Hence the traders do not derive an option value from holding capacity in the direction where - given their time one information - prices are lower.

The weak predictive quality of the interconnector fees creates profit opportunities for the non-participating traders. Given the equilibrium fees, any of these traders could use its own signal to buy capacity in the one direction that is underpriced considering its private signal; such a trade would yield a strictly positive expected payoff; hence limited market participation is not profit maximizing, at least form a purely static perspective.

\section{Quantitative Results}

In the case of the European electricity market, we can easily determine that the data are not in line with the theoretical prediction if all informed traders participate. Our task is made easy because the lower price is almost always zero; thus, we know immediately that we can essentially neglect interim information; a fact we should have expected given that only two and a half hours elapse between the interconnector auction and the spot markets. Without interim information, we just have to compare the variance of interconnector prices with the variance of the spot market differential to obtain a measure of integration. In other markets, however, we may encounter non-trivial amounts of interim information. To de-

termine the degree of integration in these markets, we need a more robust way to account for interim information. In the following, we calibrate a version of our theoretical model that captures all three types of information. Thus, we can quantify how much of the variance of the price differential is information cross-border traders have, how much is interim information, and how much is the information possessed by non-participating firms.

To do so we write the price differential as a random variable $\widetilde{\Delta p}$, which is a 
sum of variables, namely:

$$
\Delta p \equiv \delta+d_{0}+d_{1}+d_{2}
$$

where $\delta$ is the deterministic unconditional expectation of the price differential and $d_{0}, d_{1}$, and $d_{2}$ are i.i.d., normally distributed variables with mean zero, where

- $d_{0}$ with variance $\sigma_{0}^{2}$ represents the information the $\hat{N}$ firms have that trade in stage one,

- $d_{1}$ with variance $\sigma_{1}^{2}$ represents public interim information,

- and $d_{2}$ with variance $\sigma_{2}^{2}$ represents the information of the $N-\hat{N}$ firms that were not in the market for interconnector capacity.

The random variable $\tilde{d}_{0}$ is time zero information, i.e. the information of the $\hat{N}$ firms that take part in the market for interconnector capacity. From our model, it follows that this information is contained in the interconnector prices. The expectation of the price differential conditional on this information - i.e. conditional on the prices for interconnector capacity - is:

$$
\widetilde{\Delta p} \mid\left(s_{1}, \ldots, s_{\hat{N}}\right) \sim N\left(\delta_{0}, \sigma_{1}^{2}+\sigma_{2}^{2}\right), \text { where } \delta_{0}=\delta+d_{0}
$$

The realization of $\tilde{d}_{1}$ takes place between time one and two and reflects the arrival of interim information. The price differential conditional on $\left(s_{1}, \ldots, s_{\hat{N}}, s_{I}\right)$, i.e. on all information that traders have when they decide on the utilization of their acquired capacities, is

$$
\widetilde{\Delta p} \mid\left(s_{1}, \ldots, s_{\hat{N}}, s_{I}\right) \sim N\left(\delta_{1}, \sigma_{2}^{2}\right), \text { where } \delta_{1}=\delta+d_{0}+d_{1}
$$

Finally, $\tilde{d}_{2}$ is time two information, i.e. information obtained exclusively by firms not taking part in the interconnector market but only in the spot markets. Because all traders together determine the spot market prices, the price differential 
conditional on all trader's information and the public interim information is exactly the realization of the price differential:

$$
\widetilde{\Delta p} \mid\left(s_{1}, \ldots, s_{N}, s_{I}\right)=\delta+d_{0}+d_{1}+d_{2}
$$

At time two, each trader will decide on the utilization of acquired capacity depending on the sign of the mean of the expected price differential after interim information; i.e. the sign of $\tilde{\delta}_{1}$. From the perspective of time zero, $\tilde{\delta}_{1}$ is a random variable that is normally distributed with mean $\delta_{0}$ and variance $\sigma_{1}^{2}$. Given that we know from our theoretical model that equilibrium interconnector fees aggregate all information, we can calculate them as the integral over the profits for those realizations of interim information for which it is profitable to utilize the capacity in the respective direction:

$$
f^{H A *}=E\left(\tilde{\delta}_{1} \mid d_{0}, \delta_{1}>0\right)=\int_{0}^{\infty} \delta_{1} \frac{\phi\left(\frac{\delta_{1}-\delta_{0}}{\sigma_{1}^{2}}\right)}{1-\Phi\left(\frac{0-\delta_{0}}{\sigma_{1}^{2}}\right)} d \delta_{1}
$$

and

$$
f^{A H *}=(-1) \cdot E\left(\tilde{\delta}_{1} \mid d_{0}, \delta_{1}<0\right)=-\int_{-\infty}^{0} \delta_{1} \frac{\phi\left(\frac{\delta_{1}-\delta_{0}}{\sigma_{1}^{2}}\right)}{\Phi\left(\frac{0-\delta_{0}}{\sigma_{1}^{2}}\right)} d \delta_{1},
$$

where $\phi(\cdot)$ is the p.d.f. and $\Phi(\cdot)$ is the c.d.f. of the standard Normal distribution.

Note that if interim information becomes negligible the probability mass of the distribution of $\delta_{1}$ becomes concentrated around $\delta_{0}$. This implies that

$$
\lim _{\sigma_{1}^{2} \rightarrow 0} E\left(f^{H A *} \mid d_{0}\right)= \begin{cases}\delta_{0}, & \text { if } \delta_{0}>0 \\ 0, & \text { if } \delta_{0} \leq 0\end{cases}
$$

and

$$
\lim _{\sigma_{1}^{2} \rightarrow 0} E\left(f^{A H *} \mid d_{0}\right)= \begin{cases}0, & \text { if } \delta_{0} \geq 0 \\ -\delta_{0}, & \text { if } \delta_{0}<0\end{cases}
$$

Hence, the fees converge to the fees in the model without interim information. In this sense, our quantitative model also captures the case without interim infor- 
mation.

To take the model to the data, it is useful to construct two more variables. Let

$$
\bar{f}= \begin{cases}f^{H A *}, & \text { if } f^{H A *} \geq f^{A H *}, \\ -f^{A H *}, & \text { if } f^{H A *}<f^{A H *},\end{cases}
$$

be the higher one of the two equilibrium fees and

$$
\underline{f}= \begin{cases}f^{H A *}, & \text { if } f^{H A *} \leq f^{A H *}, \\ -f^{A H *}, & \text { if } f^{H A *}>f^{A H *},\end{cases}
$$

the lower one. For $\sigma_{1}^{2} \rightarrow 0$, we are back in the situation without interim information, and the lower of the two prices will be almost always zero because there is no option value. Formally, this means that the unconditional variance of $\underline{f}, \underline{\sigma}^{2}$, goes to zero:

$$
\lim _{\sigma_{1}^{2} \rightarrow 0} \underline{\sigma}^{2}=0 .
$$

Likewise, vanishing interim information implies that $\bar{f}$ will be very close to $\delta_{0}$. Formally, this means that the unconditional variance of $\bar{f}, \bar{\sigma}^{2}$ goes to $\sigma_{0}^{2}$ :

$$
\lim _{\sigma_{1}^{2} \rightarrow 0} \bar{\sigma}^{2}=\sigma_{0}^{2}
$$

Note that $\underline{\sigma}^{2}$ increases in $\sigma_{1}^{2}$, while $\bar{\sigma}^{2}$ decreases in $\sigma_{1}^{2}$.

The aim of the following calibration exercise is to make our basic intuition precise by using the observed variances, $\sigma^{2}, \underline{\sigma}^{2}$, and $\bar{\sigma}^{2}$ to calculate the underlying variances of the different kinds of information: $\sigma_{0}, \sigma_{1}$ and $\sigma_{2}$. We use the following procedure:

From the data, we know the unconditional expectation of the price differential $\delta$ and the unconditional variance $\sigma^{2}$. Moreover we know $\bar{\sigma}^{2}$ and $\underline{\sigma}^{2}$. From the latter two, the two parameters $\sigma_{0}^{2}$ and $\sigma_{1}^{2}$ are identified. $\sigma_{2}^{2}$ can be calculated as the residual variance according to

$$
\sigma_{2}^{2}=\sigma^{2}-\sigma_{0}^{2}-\sigma_{1}^{2}
$$


We find numerically values for $\sigma_{0}^{2}$ and $\sigma_{1}^{2}$ that match $\bar{\sigma}^{2}$ and $\underline{\sigma}^{2}$ by the following simulation procedure.

1. We start with some values $\sigma_{0}^{2}$ and $\sigma_{1}^{2}$.

2. We draw many (1 million) signals $s_{0}$ from a Normal distribution with mean zero and variance $\sigma_{0}^{2}$.

3. Using $\sigma_{1}^{2}$ we calculate $\underline{f}$ and $\bar{f}$ for each $s_{0}$.

4. From the resulting sample we calculate $\underline{\sigma}^{2}$ and $\bar{\sigma}^{2}$.

5. Iteratively we adjust $\sigma_{0}^{2}$ and $\sigma_{1}^{2}$ until $\underline{\sigma}^{2}$ and $\bar{\sigma}^{2}$ match the empirically observed values.

Using data from the German-Danish and the German-Dutch border and denoting Germany by home and Denmark by abroad we collect the following values for the observable variances (Table 4):

Table 4: Observed Values

\begin{tabular}{lrr}
\hline \hline & Germany/Denmark & Germany/Netherlands \\
\hline$\delta$ & 1.4 & -8.28 \\
$\sigma^{2}$ & 606.5 & $2,777.9$ \\
$\underline{\sigma}^{2}$ & 0.13 & 0.05 \\
$\bar{\sigma}^{2}$ & 219.5 & 658.2 \\
\hline \hline
\end{tabular}

Using the above described procedure, as the main results we get:

Table 5: Calibration Results

\begin{tabular}{rrr}
\hline & Germany/Denmark & Germany/Netherlands \\
\hline$\sigma_{0}^{2}$ & 219.1 & 654.4 \\
$\sigma_{1}^{2}$ & 0.5 & 0.2 \\
$\sigma_{2}^{2}$ & 386.4 & $2,123.3$ \\
\hline \hline
\end{tabular}


We can conclude that a highly similar picture emerges in the two cases: There is essentially no interim information ( $\sigma_{1}^{2}$ is close to zero), which accords well with the observation that lower prices are almost always zero. But just between a quarter and a third of the final information is included in the interconnector capacity prices: $\sigma_{0}^{2} / \sigma^{2} \approx 0.24$ for the German Dutch border and $\sigma_{0}^{2} / \sigma^{2} \approx 0.36$ for the German Danish border. Given that a large part of the available information should be public (for example, weather, business cycle, holidays, ... ), this indicates that firms with a significant amount of private information do not participate in the interconnector market.

\section{Discussion}

Given the prices we observe, there seem to be firms which have private information but do not use it. These firms could (on average) make profits by trading in the market, but they do not do so. We can conclude that these firms do not maximize expected per period payoff. One hypothesis that would be consistent with the observed prices is that national electricity providers do not compete with each other cross-border to avoid the price reductions arising from this, which can be significant as shown by Borenstein, Bushnell, and Stoft (2000). Such a collusive arrangement could be an equilibrium in a repeated game.

The industry structure of the markets makes such an explanation not unlikely. Electricity markets are highly concentrated: In Germany, the share of total production capacity (installed capacity) of the three largest firms is 69\%, in Denmark it is $72 \%$, in the Netherlands it is $69 \%$. At the same time, a large part of the electricity market is still an OTC (over the counter, i.e. bilateral trades) market (for Germany, $88 \%$ of the market is OTC, in Denmark it is $62 \%$, for the Netherlands it is $85 \%) \cdot{ }^{14}$ Thus, it could be a motivation to exploit market power in the home

\footnotetext{
${ }^{14}$ Data are from the contributions of the Danish, Dutch and German energy regulators' annual reports to the European Commission 2005. The figure for Germany includes the $7 \%$ capacity of STEAG, which is contracted long term to RWE. Downloadable from ERGEG's (European Regulators Group for Electricity and Gas) website, http://www.ergeg.org/ portal/page/portal/ERGEG_HOME/ ERGEG_DOCS/ NATIONAL_REPORTS/2005.
} 
market, in particular, on the OTC markets, and mutually abstain from competing in the neighboring market, where entry is easiest on the wholesale level (i.e. at the electricity exchanges). This is in line with the view of the Danish competition authority:

Cross border trade in the Danish-German interconnector functions poorly. These elements mean that the dominant players in West and East Denmark are not exposed to effective competition. 15

The dominant power producer thus might have a lot to lose from increased cross-border competition. At the same time, it is reasonable to assume that large producers have a lot of price relevant information that is not available to pure electricity traders. While a lot of information is public (like weather conditions, fuel prices), important supply side information is proprietary, in particular the actual availability of production capacity (e.g. power plant outages due to revisions, repair or maintenance).

Thus, large, well-informed producers might forgo relatively small profits from cross-border trading, in order to protect the dominant position in the home market. This is also reflected in the view of the European Commission on the behavior of European Electricity incumbents:

Cross-border sales do not currently impose any significant competitive constraint. Incumbents rarely enter other national markets as competitors. (Commission" 2007, para. 21)

Thus, it is likely that mainly pure traders, who want to exploit trading opportunities between the regions, are active and determine the interconnector price. Since a significant part of the information is missing, transportation prices are only a bad predictor of the spot market prices (although correct on average). Prices in the opposite direction are zero because there seems to be little interim information.

\footnotetext{
${ }^{15}$ Regulator's Annual Report to the European Commission - 2005. Contribution for Denmark compiled by Danish Energy Regulatory Authority, p. 13.
} 
To summarize: If only poorly informed traders trade in the interconnector market, but all traders (including the traders of the large incumbents) take part in the spot market, it will not be surprising to see a large variation between interconnector prices and the spot market prices. We believe that this is a convincing explanation of the data. However, as far as collusion is concerned, it is speculative.

\section{Conclusion}

We have analyzed a situation in which a commodity is traded in two connected spot markets. The commodity can be shipped between the two markets, but this incurs transportation costs. Firms first have to buy transportation capacity and afterwards submit demand functions or supply functions in the spot market. If spot markets are integrated, only specific combinations of transport prices and spot market prices are possible. If all firms participate in both steps (transport market and spot market), either (i) transport prices already include all the information and they perfectly predict the spot market prices. This obtains if no new information becomes available between the two steps. Or (ii), with interim information, transport prices do not perfectly predict the spot market prices; but then, transport prices must never be zero in one direction, since transport capacities contain an option value. Alternatively, if not all informed firms participate in the transport market, we expect the transport prices to correctly predict the spot prices only on average, even in the absence of interim information.

The data from the electricity markets suggest that the last hypothesis is the only one consistent with the data. Given the underlying market structure, it could be a plausible explanation that well informed producing companies do not participate intensively in cross-border activities in order to exploit market power in the own region. This assumes some sort of collusive behavior of large producers between the two regions.

Although this is not an example of a violation of the 'no-arbitrage' principle in the strict sense (since informed traders who do not participate can make profits only on average, and exploiting the option value of the transport capacity also in- 
volves some risk), the results suggest that 'inefficiencies' can persist in commodity markets. Our explanation for this empirical finding rests on the idea that traders are asymmetric. Some traders might have addition interests at stake, preventing them from exploiting all profit opportunities.

Though our paper focuses on the electricity markets, the approach and the calibration method might also be of interest in other contexts. It is often interesting to know whether commodity markets are 'global' or still mainly 'regional' or 'local', i.e. whether the difference in the prices observed at different commodity exchanges are only due to transportation costs, or whether firms still mainly buy and sell in their 'home market' and do not compete for supply and demand across different regions. From an efficiency point of view, global markets will usually be preferred due to the higher level of competition. For the same reason, players with market power in regional markets will usually prefer to keep markets regional and avoid cross-market competition. For instance, European national electricity incumbents probably prefer a situation with national monopolies or oligopolies to a unified European electricity market with European-wide competition.

Often it will be difficult to judge from the spot market prices alone whether differences in spot market prices in different regions are due to a lack of crossmarket competition or due to transportation costs. The approach used in this paper might help in providing answers with the help of market data not only from the "downstream" spot market but also from the 'upstream' market for transport capacity, provided such data is available.

Even if the transport market is not organized in an exchange, data on the prices for transport capacities - e.g. for shipping capacities, freight trains, road transport and the like - might also be informative and allow some conclusions on the question whether regional markets form a unified market or are distinct. 


\section{References}

Borenstein, S., J. Bushnell, and S. Stoft (2000): "The Competitive Effects of Transmission Capacity in a Deregulated Electricity Industry," The RAND Journal of Economics, 31, 294-325.

CEER (2003): "Completing the Internal Energy Market: The Missing Steps," Press statement, October 2003, download under http://www.ceer-eu.org/.

Cochrane, J. H. (1991): "Volatility tests and efficient markets. A review essay," Journal of Monetary Economics, 27, 463-485.

Commission", E. (2007): "Energy Market Sector Inquiry," Inquiry pursuant to Article 17 of Regulation (EC) No 1/2003 into the European gas and electricity sectors, $\operatorname{COM}(2006) 851$ final (published 10.1.2007).

Crampes, C., and J.-J. Laffont (2001): "Tranport Pricing in the Electricity Industry," Oxford Review of Economic Policy, 17, 313-328.

European Commission (2004): "Medium Term Vision for the Internal Electricity Market," DG Energy and Transport Working Paper, 01/03/2004.

Grossman, S. (1976): "On the Efficiency of Competitive Stock Markets Where Traders Have Diverse Information," Journal of Finance, 31, 573-585.

Hellwig, M. F. (1980): "On the Aggregation of Information in Competitive Markets," Journal of Economic Theory, 22, 477-498.

Hobbs, B. F., F. A. Rijkers, and M. G. Boots (2005): "The More Cooperation, the More Competition? A Cournot Analysis of the Benefits of Electric Market Coupling," Energy Journal, 26, 69-97.

Höffler, F., And T. Wittmann (2007): "Netting of Capacity in Interconnector Auction," Energy Journal, 28, 113-144.

Shiller, R. J. (1981): "The Use of Volatility Measures in Assessing Market Efficiency," The Journal of Finance, 36, 291-304. 
Turvey, R. (2006): “Interconnector Economics," Energy Policy, 34, 1457-1472.

Zachmann, G. (2007): "Electricity Wholesale Market Prices in Europe: Convergence?," DIW Working Paper (German Institute for Economic Research, Berlin). 


\section{Appendix: Proofs}

Proof of Proposition 1: Note that for any value of $S_{N}$ the larger of the two equilibrium fee is strictly monotonic in $S_{N}$. To prove that $f^{H A *}$ and $f^{A H *}$ are an equilibrium, note first that due to the strict monotonicity of the fees in $S_{N}$ the traders can infer $S_{N}$ from the fees in equilibrium. Second, the distribution of $\widetilde{\Delta p}$ given $S_{N}$ is the same as the distribution given $S_{N}$ and any $s_{n}\left(S_{N}\right.$ is a sufficient statistic for $\left.\left(S_{N}, s_{n}\right)\right)$. In equilibrium, all traders expect the same profits $\pi^{H A}\left(S_{N}\right)=\max \left\{-\delta-S_{N}, 0\right\}$ and $\pi^{A H}\left(S_{N}\right)=\max \left\{\delta+S_{N}, 0\right\}$ from owning capacity. If $f^{H A *}=\pi^{H A}\left(S_{N}\right)$ and $f^{A H *}=\pi^{A H}\left(S_{N}\right)$, they are just indifferent between buying or not, and they can be allocated $\bar{K}$ units of capacity in both directions so that both markets clear.

For uniqueness, suppose that there is a different set of fees, $f^{* \prime}=\left(f^{H A *^{\prime}}, f^{A H *^{\prime}}\right)$, that also are fully revealing; i.e., all traders know the realization of $S_{N}$. At least one element of $f^{* \prime}$ cannot be equal to the expected profits from owning capacity in this direction, and demand must be either zero or infinity for this direction so that $f^{* \prime}$ cannot be an equilibrium; hence the equilibrium must be the only fully revealing rational-expectations equilibrium.

Proof of Proposition 2:Note that both equilibrium fees are strictly monotonic in $S_{N}$ :

$$
\begin{aligned}
& \frac{\partial f^{H A *}\left(S_{N}\right)}{\partial S_{N}}=\Phi\left(\frac{S_{N}}{\sigma_{I}}\right)>0, \text { and } \\
& \frac{\partial f^{A H *}\left(S_{N}\right)}{\partial S_{N}}=-\left[1-\Phi\left(\frac{S_{N}}{\sigma_{I}}\right)\right]<0,
\end{aligned}
$$

To prove that $f^{H A *}$ and $f^{A H *}$ are an equilibrium, note first that due to the strict monotonicity of the fees in $S_{N}$ the traders can infer $S_{N}$ from of either of the fees in equilibrium. Second, the distribution of $\widetilde{\Delta p}$ given $S_{N}$ is the same as the distribution given $S_{N}$ and any $s_{n}\left(S_{N}\right.$ is a sufficient statistic for $\left.\left(S_{N}, s_{N}\right)\right)$. In 
equilibrium, all traders expect the same profits

$$
\pi^{A H}\left(S_{N}\right)=\int_{\delta+S_{N}}^{\infty}\left[\delta+S_{N}+s_{I}\right] \phi\left(\frac{s_{I}}{\sigma_{I}}\right) d s_{I},
$$

and

$$
\pi^{H A}\left(S_{N}\right)=-\int_{-\infty}^{-\delta-S_{N}}\left[\delta+S_{N}+s_{I}\right] \phi\left(\frac{s_{I}}{\sigma_{I}}\right) d s_{I} .
$$

from owning capacity. If $f^{H A *}=\pi^{H A}\left(S_{N}\right)$ and $f^{A H *}=\pi^{A H}\left(S_{N}\right)$, they are just indifferent between buying or not, and they can be allocated $\bar{K}$ units of capacity in both directions so that both markets clear.

For uniqueness, suppose that there is a different set of fees, $f^{* \prime}=\left(f^{H A *^{\prime}}, f^{A H *^{\prime}}\right)$, that also are fully revealing; i.e., all traders know the realization of $S_{N}$. At least one element of $f^{* \prime}$ cannot be equal to the expected profits from owning capacity in this direction, and demand must be either zero or infinity for this direction so that $f^{* \prime}$ cannot be an equilibrium; hence the equilibrium must be the only fully revealing rational-expectations equilibrium. 